\title{
Organik ve Mineral Gübre Uygulamalarının Patates (Solanum tuberosum L.) Bitkisinde Verim ve Toprak Mikrobiyal Aktivitelerine Etkisi
}

\author{
Mehmet Bahadırl1 ${ }^{1 *}$, Kemal Doğan ${ }^{2}$ \\ ${ }^{1}$ Hatay Mustafa Kemal Üniversitesi, Fen Bilimleri Enstitüsü, Hatay, Türkiye (ORCID: 0000-0002-1242-6485), mhmtbhdrl@gmail.com \\ ${ }^{2}$ Hatay Mustafa Kemal Üniversitesi, Ziraat Fakültesi, Toprak Bilimi ve Bitki Besleme Bölümü, Hatay, Türkiye (ORCID: 0000-0002-5448-0009), \\ dogankem@hotmail.com
}

(İlk Geliş Tarihi Aralık 2020 ve Kabul Tarihi Ocak 2021)

(DOI: $10.31590 /$ ejosat.846045)

ATIF/REFERENCE: Bahadırl, M. \& Doğan, K. (2021). Organik ve Mineral Gübre Uygulamalarının Patates (Solanum tuberosum L.) Bitkisinde Verim ve Toprak Mikrobiyal Aktivitelerine Etkisi. Avrupa Bilim ve Teknoloji Dergisi, (22), 140-145.

Öz

Bu araştırmada, Hatay ili Reyhanlı ilçesinde ana ürün olarak yetiştirilen patates (Solanum tuberosum L.) bitkisinde, organik ve mineral gübre uygulamalarının, verim ve bazı toprak mikrobiyal aktivitelere etkilerinin belirlenmesi amaçlanmıştır. Çalışma, 2019-2020 yıllarında tesadüf bloklarında bölünmüş parseller deneme desenine göre üç yinelemeli olarak yürütülmüştür. Ana parsellerde çeşitler (Madeleine-Ç1, Melody-Ç2), alt parsellerde ise gübre uygulamaları (mineral gübre (MG1; MG2), ahır gübresi (AG1; AG2), solucan gübresi (SG1; SG2), Kompoze organik (AG1; SG1) ve organo-mineral (MG/2ÇG1; MG/2SG1)) yer almıştır. Çalışmada parsellerin yumru verimi, toprak solunumu ( $\mathrm{CO}_{2}$ üretimi), dehidrogenaz enzim aktivitesi (DHA) ve mikrobiyal biyomas karbon (MBC) içerikleri belirlenmiştir. Araştırma sonuçlarına göre en yüksek verim değerleri Madeleine çeşidinde kompoze organik gübre uygulamasından (AG1SG1) $5701 \mathrm{~kg} \mathrm{da}^{-1}$ olarak elde edilmiştir. $\mathrm{CO}_{2}$ aktivitesi 9,3-17,3 $\mu \mathrm{g}$ gkt ${ }^{-1}$ aralığında değişim gösterirken en yüksek Madeleine çeşidinde AG2 uygulamasından elde edilmiştir. DHA değerleri 152,7-675,2 $\mu \mathrm{g}$ TPF $\mathrm{gkt}^{-1}$ aralığında değişim gösterirken en yüksek Melody çeşidinde AG2 uygulamasında belirlenmiştir. MBC değerleri 64,2-222,6 $\mu \mathrm{g} \mathrm{gkt}^{-1}$ en yüksek Melody çeşidinde AG2 uygulamasında belirlenmiştir. $\mathrm{CO}_{2}$ ve DHA aktivitesi çeşit farklılığında istatistiki olarak etkilenmezken yumru verimi ve MBC aktivitesi etkilendiği belirlenmiştir. Araştırma sonuçlarına göre organik ve organo-mineral uygulamaların incelenen parametreler üzerinde istatistiki açıdan önemli $(\mathrm{p}<0,05)$ artışlara neden olduğu tespit edilmiştir.

\section{The Effect of Organic and Mineral Fertilizer Applications on Yield and Soil Microbial Activities in Potato (Solanum tuberosum L.)}

\begin{abstract}
This research was carried out to determine the effects of organic and mineral fertilizer applications on yield and some soil microbial activities in two potato (Solanum tuberosum L.) varierities (Madeleine and Melody). In this research, two potato varieties were cultivated in Reyhanlı (Hatay) field conditions during 2019-2020. The field trials were design as randomized block design split plots with three replicates. Varieties were in main plots while fertilizers were in sub-plots. Fertilizer apllications were mineral fertilizer (MG1; MG2), barn manure (AG1; AG2), worm manure (SG1; SG2), compozed organic (AG1; SG1) and organo-mineral (MG / 2ÇG1; MG / 2SG1). In the study, tuber yield $\left(\mathrm{kg} \mathrm{da}^{-1}\right)$, soil respiration $\left(\mathrm{CO}_{2}\right.$ production), dehydrogenase enzyme activity (DHA) and microbial biomass carbon (MBC) contents were determined. The highest yield values were obtained from the compozed organic fertilizer application (AG1SG1) as $5701 \mathrm{~kg} \mathrm{da}^{-1}$ in the Madeleine variety. $\mathrm{CO}_{2}$ activities varied between 9,3-17,3 $\mu \mathrm{g}$ gkt ${ }^{-1}$, while the highest result was obtained from AG2 application in Madeleine variety. DHA values varied between 152,7-675,2 $\mu \mathrm{g}$ TPF gkt ${ }^{-1}$, the highest result was determined in AG2 application in Melody variety. MBC values were ranged between 64,2-222,6 $\mu \mathrm{g}$ gkt ${ }^{-1}$, the highest result were obtained in the AG2 application in the Melody variety. The results showed that $\mathrm{CO}_{2}$ and DHA activity were not statistically affected by
\end{abstract}

*Sorumlu Yazar: mhmtbhdrl@gmail.com 
variation, however tuber yield and MBC activity were found affected by the varieties. According to the results of the research, it was determined that organic and organo-mineral applications caused statistically significant $(\mathrm{p}<0,05)$ increases on the parameters examined.

Keywords: Vermicompost, Farm Manure, Soil Microbial Activity, Potato.

\section{Giriş}

İnsan beslenmesinde çok önemli bir yere sahip olan patates (Solanum tuberosum L.) dünyada pirinç, misır ve buğdaydan sonra gelen en önemli yiyecek ürünüdür (Karam et al., 2009; Kandil et al., 2011; Suh, 2015). Anavatanı Güney Amerika'nın And dağları olan patatesin buradan Avrupa'ya ve daha sonra Kafkaslar üzerinden ülkemize geldiği düşünülmektedir. Günümüzde kuzey ve güney yarım kürede çok geniş iklim kuşaklarında yetiştiriciliği yapılabilmektedir. Dünyada patates üretimi 17,5 milyon ha alanda 368 milyon ton olarak gerçekleşmektedir. Bu üretimin \%51'i sırasıyla Çin, Hindistan ve Rusya'da yapılmaktadır ve Türkiye bu listede 16. sırada yer almaktadır (FAO 2018). Ülkemizde patates yetiştiriciliği 140.896 ha alanda yapılırken toplam üretim yaklaşık 5 milyon ton olup ortalama verim 353,8 kg/ha olarak belirtilmiştir (TÜİK, 2019). Ülkemizin hemen her bölgesinde (yaklaşık 66 il) yetiştirilmekle birlikte, Niğde, Afyonkarahisar ve Konya illeri toplam üretimin yaklaşık \%40'ını karşılamaktadır. Hatay ilinde ise özellikle Reyhanlı, Kumlu ve Antakya ilçelerinde üretimi yapılmaktadır, ilin toplam ekim alanı 1837,9 ha alanda olup üretim miktarı 69230 tondur (TÜİK, 2019).

Kimyasal gübreler, tarımsal üretimlerde verimi arttırdı̆̆ 1 için büyük talepte görmekte ve yaygın olarak kullanılmaktadır. Dengeli ve ekonomik olmak koşulu ile gübrelemenin diğer tüm tarımsal girdilere göre bitkisel üretimde verim üzerindeki payının daha yüksek olduğu yapılan araştırmalarla kanıtlanmış durumdadır. Gübre kullanımının bitkisel üretim artışındaki payı \%50-75 arasında değişmekte olup, ülkemiz ve dünyanın her yerinde bitkisel verim artışı ve gübre tüketimi arasında çok yüksek bir ilişki vardır (Eyüpoğlu, 2002; Polat, 2020). Taban ve nitratlı gübrelerde katkı maddesi olarak kullanılan kireç taşı, kil ve dolamit haricinde gübre üretiminde kullanılan girdiler tamamen ithal olarak temin edilmektedir. Hergeçen gün artan nüfusu besleme kaygılarıyla uygulama oranı artan kimyasal gübreler, verimli toprakların azalmasına neden olmaktadır. Düzensiz ve aşırı kimyasal gübre uygulamaları besin elementi döngülerine, mikrobiyal aktivitelere, çevresel sorunlara ve pahalı önlemlere neden olduğu için biyolojik gübrelemeler önem kazanmaya başlamıştır (Kannaiyan, 2002; Taheri ve ark., 2012). Organik gübre uygulamaları ürün verim ve kalitesini önemli derecelerde etkilemektedir. Aşırı mineral gübre kullanımı yanında azalan organik materyal içerikleri tarım topraklarımızın kalite unsurlarını tehdit etmektedir (Sarığlu ve ark., 2017). Organik gübrelemenin yalnızca besin elementi sağlama açısından değil aynı zamanda toprakta düzenleyici özellikleri ile sürdürülebilir verimlilik unsurlarını muhafaza etmesi gibi etkilerle de verimin artmasında önemli bir rol üstlenmiştir. (Tejada et al., 2003; Perez et al., 2007; Sarığlu, 2017).

Patates yetiştiriciliğinde öncelikli olarak mineral gübreler kullanılırken günümüzde organik gübrelerin tek başına ya da mineral gübrelerle uygulanması önem kazanmıştır. Yapılan pek çok çalışma ile patates yetiştiriciliğinde organik ve organomineral gübre uygulamalarının mineral gübre uygulamaları ile verim ve kalite açısından benzer sonuçlar ortaya koyduğu görülmüştür. Kurt (2019), tarafından yürütülen bir çalışmada azot+solucan gübresi uygulamasının fosfor+solucan gübresi, amonyum sülfat, triple süper fosfat uygulamalarına göre verimi daha fazla arttırdığg tespit edilmiştir. Benzer bir çalışmada mineral gübrelerin tek başına ve organik gübrelerle birlikte kullanıldığı uygulamalarda en yüksek yumru verimi organomineral gübre uygulamasından elde edilmiştir (Boke, 2014). İlaveten pek çok çalışmada kompost, fermente gübre ve solucan gübresinin mineral gübre yerine tercih edilebileceği belirtilmiştir (Eleroğlu ve Korkmaz, 2016; Yourtchi ve ark., 2013).

Farklı gübre karışımlarının, toprak kalite unsurlarından mikrobiyal aktivitelere olumlu etkileri olduğu ve tarımsal maliyetleri düşürdüğü bazı araştırmacılar tarafından belirlenmiştir (Stark ve ark., 2007; Cerny ve ark., 2010). Mandic ve ark. (2011) tarafindan yapılan bir araştırmada patates bitkisinde farklı organik ve mineral gübrelemeler kullanılarak toprak mikrobiyal aktivitelere etkileri araştırılmış ve araştırma sonuçlarına göre çiftlik gübresi uygulamalarının patates verimini ve toprak mikrobiyal aktivitelerini arttırdığı belirlenmiştir. Benzer bir araştırma sonuçlarına göre Suh ve ark., (2015), Kamerun'da patates bitkisinde organik ve mineral gübre uygulamalarının bitki gelişimi ve verime etkilerini belirlemişlerdir. Araştırma sonuçlarına göre, mineral gübre uygulamaları toprak $\mathrm{pH}$ 'n düşürmüş, çiftlik gübresi ise, organik madde oranını, değişebilir katyonları arttırmıştır. Organik ve mineral gübrelerle yapılan başka bir araştırmada Ioveno ve ark. (2009), Akdeniz iklimi topraklarında toprak solunumu $\left(\mathrm{CO}_{2}\right.$ üretimi) ve enzim aktivitelerini belirlemişlerdir. Araştırma sonuçlarına göre, organik materyal uygulamalarının toprak mikrobiyal aktivitelerini arttırdığ1 tespit edilmiştir.

$\mathrm{Bu}$ araştırmada, Hatay ili koşullarında farklı patates çeşitlerine uygulanan solucan, çiftlik ve kimyasal gübre dozlarının verim ve kök bölgesi mikrobiyal aktivite parametrelerinden toprak solunumu, enzim aktivitesi ve mikrobiyal biyomas karbon içeriklerine etkileri araştırılmıştır.

\section{Materyal ve Metot}

Bu çalışma Hatay ili Reyhanlı ilçesi çiftçi koşullarında 2019. 2020 yıllarında yürütülmüştür. Deneme materyali olarak bölgede en çok yetiştiriciliği yapılan çeşitlerden Madeleine (erkenci) ve Melody (orta-erkenci) çeşitleri seçilmiştir.

Araştırma toprakları Reyhanlı toprak serisi özellikleri göstermektedir. Söz konusu seri topraklar $\mu 1$ alüviyal ana materyallerin depolandığı nehir terasları üzerinde oluşmuştur. Düz eğimde oluşan seri toprakları derin profilli ve AC horizon dizilimine sahiptirler (Kılıç ve ark., 2008). Deneme alandan alınan toprak örnekleri üzerinden yapılan analiz sonuçlarına göre, pH 7,85, tuz \%0,024, kireç \%27, organik madde $\% 0,65, \mathrm{~K}_{2} \mathrm{O} 93$ $\mathrm{kg} \mathrm{da}^{-1}, \mathrm{P}_{2} \mathrm{O}_{5} 3,21 \mathrm{~kg} \mathrm{da}^{-1}$ ve toprak bünye sınıfı killi tın olarak belirlenmiştir. Deneme öncesi toprakların $\mathrm{CO}_{2}, \mathrm{DHA}$ ve $\mathrm{MBC}$ içerikleri ise sırasıyla $8,3 \mu \mathrm{g} \mathrm{g} \mathrm{kt}^{-1}, 122,4 \mu \mathrm{g}$ TPF $\mathrm{g} \mathrm{kt}^{-1}$ ve 82,3 $\mu \mathrm{g} \mathrm{g} \mathrm{kt}^{-1}$ olarak belirlenmiştir. Araştırmada kullanılan solucan gübresinin ( $\mathrm{SG}) \mathrm{pH}$ değeri 7.5, organik madde içeriği $\% 43$ ve $\mathrm{N}$, $\mathrm{P} 2 \mathrm{O} 5, \quad \mathrm{~K} 2 \mathrm{O}$ değerleri ise sirasıyla \%2,4-2,1-2,3 olarak bulunurken çiftlik gübresi (ÇG) organik madde içeriği, \%48, N, $\mathrm{P}, \mathrm{K}$ içerikleri sırasıyla \%1,8-0,15-0,67'dir. $\mathrm{pH}$ değeri ise 7,8 
olarak belirlenmiştir. Denemenin yürütüldüğü bölgenin iklimi, tipik Akdeniz iklim özelliklerine sahip, yazlar sıcak ve kurak, kışlar 1 lık ve yağışlıdır, yetiştiriciliğin yapıldığ 1 şubat-temmuz aylarına ait 2019, 2020 ve uzun yıllar iklim (UYO) verileri Tablo 1.'de verilmiştir. Tablo değerleri incelendiğinde yetiştiricilik döneminde her iki yılda da ortalama sıcaklık uzun yıllar ortalamasıyla benzerlik gösterirken, toplam yağış miktarında farklılıklar olduğu görülmüştür.

Tablo 1. Deneme Alanına Ait İklim Özellikleri*

\begin{tabular}{lllllll}
\hline \multirow{2}{*}{ Aylar } & \multicolumn{3}{c}{ Ortalama sicaklık $\left({ }^{\circ} \mathbf{C}\right)$} & \multicolumn{3}{c}{ Toplam yağıș (mm) } \\
\cline { 2 - 7 } & $\mathbf{2 0 1 9}$ & $\mathbf{2 0 2 0}$ & UYO & $\mathbf{2 0 1 9}$ & $\mathbf{2 0 2 0}$ & UYO \\
\hline Şubat & 10,51 & 9,58 & 11,8 & 42,0 & 95,0 & 75,2 \\
\hline Mart & 12,97 & 14,94 & 15,8 & 55,6 & 77,0 & 10,2 \\
\hline Nisan & 16,37 & 18,10 & 19,2 & 60,6 & 54,0 & 15,0 \\
\hline Mayis & 23,85 & 23,24 & 23,8 & 0,4 & 26,0 & 18,0 \\
\hline Haziran & 27,65 & 25,2 & 26,5 & 1,0 & 10,0 & 3,8 \\
\hline Temmuz & 29,03 & 29,54 & 28,8 & 0,4 & 1,0 & 0,4 \\
\hline Ortalama/Toplam & $\mathbf{2 0 , 0 6}$ & $\mathbf{2 0 , 1 0}$ & $\mathbf{2 0 , 9 8}$ & $\mathbf{1 6 0 , 0}$ & $\mathbf{2 6 3 , 0}$ & $\mathbf{1 2 2 , 6}$ \\
\hline
\end{tabular}

*Hatay Meteoroloji İl Müdürlüğü

Deneme tesadüf bloklarında bölünmüş parseller deneme desenine göre üç yinelemeli olarak kurulmuştur. Çalışmada çeşitler ana parsellere gübre uygulamaları ise alt parsellere yerleştirilmiştir. Denemede 9 farklı gübre uygulamasının (Mineral gübre (MG1;MG2), ahır gübresi (AG1;AG2), solucan gübresi (SG1;SG2), ahır+solucan gübresi (AG1+SG1), mineral+ahır gübresi $(\mathrm{MG} / 2+\mathrm{AG} 1)$ ve mineral+solucan gübresi (MG/2+SG1)) etkileri incelenmiştir.

Deneme parsel uzunlukları 5 metre, parsel genişlikleri 2,8 metre ve parseller arasında 1 metre boşluk olacak şekilde planlanmıştır. Patates yumruları, deneme topraklarına şubat ayı içerisinde ekilmiştir. Ekim öncesi mineral ve organik gübreler deneme öncesi toprak analizlerine gübre varyantlarına uygun olarak yapılmıştır. Hasat zamanına kadar bir defa ara çapası yapılmış, bir defa yabancı ot ilacı ve iklim koşullarına göre belirlenmek şartıyla farklı dönemlerde fungusit (mantar ilacı) atılmıştır. Başlardan birer sıra ve diğer kenarlardan 50'şer cm kenar tesiri olarak atılmıştır.

Toprak mikrobiyal analizleri hasat zamanı alınan kök bölgesi toprak örnekleri üzerinde hava kurusu topraklarda yapılmış ve firın kuru toprak ağırlıkları üzerinden hesaplanmıştır. Toprak mikrobiyal analizlerinden, toprak solunumu (CO2 üretimi), dehidrogenaz enzim aktivitesi (DHA) ve mikrobiyal karbon (MBC) içerikleri sırasıyla, Isermayer (1952), Thalman (1967) ve Öhlinger (1993)'e göre yapılmıştır. Tüm parsel hasat edilerek parsele yumru verimi hesaplanmıştır.

Çalışmada incelenen özelliklere ait istatistiksel veriler MSTAT-C paket programı kullanılarak tesadüf bloklarında bölünmüş parseller deneme desenine göre varyans analizine tabi tutulmuş ve ortalamalara ait istatistiksel farklılıklar DUNCAN testi ile gruplandırılmıştır.

\section{Araştırma Sonuçları ve Tartışma}

\subsection{Yumru verimi $\left(\mathrm{kg} \mathrm{da}^{-1}\right)$}

Araştırmada uygulamalar sonucunda elde edilen iki yıllık ortalama yumru verimleri Tablo 2'de verilmiştir. Yumru verimleri incelendiğinde çeşitler arasında istatistiki olarak $\% 5$ seviyesinde önemli farklılıklar olduğu görülmüştür. Çeşitlerin ortalama yumru verimleri Madeleine çeşidinde 2464-5701 kg da $\mathrm{kg}^{-1}$ aralı̆̆ında, Melody çeşidinde 2262-5030 $\mathrm{kg} \mathrm{da}$ aralı̆̆ında değişim e-ISSN: 2148-2683 göstermiştir. En yüksek yumru verimi Madeleine çeşidinden AG1SG1, (MG1/2)AG1, (MG1/2)SG1 uygulamalarından sırasıyla, 5701, 5651, $5637 \mathrm{~kg} \mathrm{da}{ }^{-1}$ tespit edilmiştir. En düşük verimler ise her iki çeşitte kontrolden elde edilmiştir.

Araştırma uygulamaları incelendiğine kompoze organik gübre (AG1SG1) ve organamineral gübre ((MG1/2)AG1, (MG1/2)SG1) uygulamalarının verim değerlerini önemle derecede artırdığı söylenebilir. Mineral gübre uygulamalarının ikinci doz uygulaması birinci doz uyuglamasından 2 kat fazla olmasına rağmen yumru verimini önemli derecede düşürmüştür. Benzer bir sonuç Çukurova koşullarında farklı azot dozlarının verime etkisinin incelendiği bir çalışmada da görülmüştür. $\mathrm{Bu}$ çalışmada değerler istatistiki olarak aynı gurpta yer alsa da artan azot dozlarıyla verimde düşüş olmuştur (Akpınar ve ark., 2019). Suh ve ark. (2015) organik ve mineral gübre karışımlarıyla patates bitkisinde yaptıkları araştırmada, en yüksek yumru verimini organomineral gübre uygulamalarından 7,63-10,87 ton $\mathrm{ha}^{-1}$ bulmuştur. Farklı azot $\left(50,100\right.$ ve $\left.150 \mathrm{~kg} \mathrm{ha}^{-1}\right)$ ve solucan gübresi $\left(4,5,9,12\right.$ ton $\left.\mathrm{ha}^{-1}\right)$ uygulamalarının patates verimine etkisinin incelendiği bir çalışmada en yüksek yumru verimi $150 \mathrm{~kg} \mathrm{ha}^{-1}$ azot gübresi ve 12 ton $\mathrm{ha}^{-1}$ solucan gübresi uygulamalarından sırasıyla $4290 \mathrm{~kg} \mathrm{da}^{-1}, 3840 \mathrm{~kg} \mathrm{da}^{-1}$ olarak elde edilmiştir (Yourtchi ve ark., 2013). Mineral, organik ve organomineral gübre uygularının yumru verimine etkisinin incelendiği farklı bir çalışmada mineral gübre uygulamalarının tek başına verim artışı için yeterli olmadığı ancak çiftlik gübresiyle birlikte uygulandığında yumru verimini arttırdığı belirlenmiştir (Boke, 2014). Bu çalışmada en yüksek verim ise çiftlik gübresi azot-fosfor-potasyum kombinasyonundan $4,13 \mathrm{~kg} \mathrm{da} \mathrm{da}^{-1}$ olarak elde edilmiştir. Akal (2016) tarafından yürütülen bir çalışmada organik, inorganik azot ve bunların kombinasyonlarının patateste yumru verimine etkisi incelendiğinde en yüksek verim 2589,2 $\mathrm{kg} \mathrm{da}^{-1}$ ile $1000 \mathrm{~kg} \mathrm{da}^{-1}$ organik gübre+7,5 $\mathrm{kg} \mathrm{N}$ da $^{-1}$ uygulamasından elde edilmiştir. Madeleine çeşidininde kullanıldığ 1 bir çalışmada organomineral (\%20 organik madde, $8-21-0+\mathrm{Zn})$, kompost $\left(1 \mathrm{t} \mathrm{da}^{-1}\right)$ gübrelerin ve tavuk gübresinin $\left(1 \mathrm{t} \mathrm{da}^{-1}\right)$ yumru verimine etkisi incelenmiştir. Çalışmada en yüksek yumru verimi Arizona çeşidinde organomineral gübre uygulamasından $9936 \mathrm{~kg} \mathrm{da}^{-1}$ olarak elde edilirken Madeleine çeşidinde uygulamalara göre verim 5588$6459 \mathrm{~kg} \mathrm{da}^{-1}$ (kompost) aralığında tespit edilmiştir (Eleroğlu ve Korkmaz, 2016). Kurt (2019) tarafindan yürütülen bir çalışmada mineral (amonyum sülfat ve triple süper fosfat) ve organik (leonardit ve solucan gübresi) gübrelerin ayrı ayrı ve birlikte 
uygulandığında patates verimine etkisi incelenmiştir. Çalışmada en yüksek verim organomineral gübre uygulamasından $3562,3 \mathrm{~kg}$ $\mathrm{da}^{-1}$ olarak elde edilmiştir. Çalışmalar değerlendirildiğinde patates üretiminde kullanılan çeşit sayısının fazla olması, yetiştirilen alanların toprak ve iklim koşullarının farklı yumru verim değerlerinde rakamsal farklılıklar ortaya koysada genel olarak mineral gübrenin tek başına kullanımı yerine organomineral gübre olarak kullanımının verim artışına olumlu etkileri olduğu söylenebilir.

Tablo 2. Gübre Uygulamalarının Yumru Verimi $\left(\mathrm{kg} \mathrm{da}^{-1}\right), \mathrm{CO}_{2}\left(\mu \mathrm{g} g \mathrm{t}^{-1}\right), \mathrm{DHA}\left(\mu \mathrm{g}\right.$ TPF $\left.g k t^{-1}\right)$ ve MBC $\left(\mu \mathrm{g} k t^{-1}\right)$ Aktivitelerine Etkileri*

\begin{tabular}{|c|c|c|c|c|c|c|c|c|}
\hline \multirow{2}{*}{$\begin{array}{l}\text { Gübre Dozları } \\
\text { Çeşitler }\end{array}$} & \multicolumn{2}{|c|}{ Yumru Verimi } & \multicolumn{2}{|c|}{$\mathrm{CO}_{2}$} & \multicolumn{2}{|c|}{ DHA } & \multicolumn{2}{|c|}{ MBC } \\
\hline & Ç1 & Ç2 & Ç1 & Ç2 & Ç1 & Ç2 & Ç1 & Ç2 \\
\hline Kontrol & $2464 \mathrm{I}$ & 2262 I & $9,3 \mathrm{CD}$ & $12,5 \mathrm{BC}$ & $152,7 \mathrm{H}$ & $156,0 \mathrm{H}$ & 90,8 H-J & $133,3 \mathrm{EF}$ \\
\hline MG1 & $5235 \mathrm{~B}$ & $4662 \mathrm{DE}$ & $15,5 \mathrm{AB}$ & $13,0 \mathrm{~A}-\mathrm{C}$ & $246,6 \mathrm{DE}$ & $250,8 \mathrm{DE}$ & $132,4 \mathrm{EF}$ & 151,3 C-E \\
\hline MG2 & $4236 \mathrm{~F}$ & $3631 \mathrm{G}$ & $13,9 \mathrm{AB}$ & $13,1 \mathrm{~A}-\mathrm{C}$ & $163,0 \mathrm{GH}$ & $249,5 \mathrm{DE}$ & $120,3 \mathrm{FG}$ & $163,7 \mathrm{CD}$ \\
\hline AG1 & $4403 \mathrm{EF}$ & 4529 D-F & $14,4 \mathrm{AB}$ & $15,8 \mathrm{AB}$ & $344,2 \mathrm{C}$ & $217,6 \mathrm{EF}$ & $166,5 \mathrm{CD}$ & 103,9 G-I \\
\hline AG2 & $4564 \mathrm{DF}$ & $4811 \mathrm{CD}$ & $17,3 \mathrm{~A}$ & $15,3 \mathrm{AB}$ & $493,5 \mathrm{~B}$ & $675,2 \mathrm{~A}$ & $168,7 \mathrm{C}$ & $222,6 \mathrm{~A}$ \\
\hline SG1 & $5043 \mathrm{BC}$ & $3671 \mathrm{G}$ & $13,7 \mathrm{AB}$ & 13,3 A-C & $200,1 \mathrm{~F}$ & 198,7 FG & $84,6 \mathrm{IJ}$ & $109,8 \mathrm{GH}$ \\
\hline $\mathrm{SG} 2$ & $5282 \mathrm{~B}$ & $5030 \mathrm{BC}$ & $13,3 \mathrm{~A}-\mathrm{C}$ & $12,4 \mathrm{BC}$ & $217,0 \mathrm{EF}$ & $223,1 \mathrm{D}-\mathrm{F}$ & $111,3 \mathrm{GH}$ & $78,1 \mathrm{JK}$ \\
\hline AG1SG1 & $5701 \mathrm{~A}$ & $4986 \mathrm{BC}$ & $14,0 \mathrm{AB}$ & $11,9 \mathrm{BC}$ & $315,6 \mathrm{C}$ & $244,2 \mathrm{DE}$ & $231,9 \mathrm{~A}$ & $64,2 \mathrm{~K}$ \\
\hline (MG1/2)AG1 & $5651 \mathrm{~A}$ & $3332 \mathrm{H}$ & $13,9 \mathrm{AB}$ & $14,5 \mathrm{AB}$ & $256,5 \mathrm{D}$ & $196,8 \mathrm{FG}$ & 199,7 B & $108,5 \mathrm{GH}$ \\
\hline (MG1/2)SG1 & $5637 \mathrm{~A}$ & $4552 \mathrm{D}-\mathrm{F}$ & $12,0 \mathrm{D}$ & $12,0 \mathrm{D}$ & $196,1 \mathrm{FG}$ & $158,4 \mathrm{H}$ & $147,3 \mathrm{DE}$ & $167,7 \mathrm{C}$ \\
\hline Genel ortalama & $4822 \mathrm{~A}$ & 4147 B & $13,7 \mathrm{~A}$ & $13,4 \mathrm{~A}$ & $258,5 \mathrm{~A}$ & $257,0 \mathrm{~A}$ & $145,3 \mathrm{~A}$ & 130,3 B \\
\hline
\end{tabular}

* Aynı harfle gösterilen ortalamalar arasında, $\mathrm{p}<0,05$ düzeyinde istatistiksel olarak fark yoktur

\section{2. $\mathrm{CO}_{2}$ Üretimi $\left(\mu \mathrm{gkt}^{-1}\right)$}

Araştırma uygulamalarının kök bölgesi topraklarının $\mathrm{CO}_{2}$ üretimine etkileri Tablo 2'de verilmiştir. Genel ortalama sonuçlarına göre, çeşitler arasındaki $\mathrm{CO}_{2}$ farklılıkları Madeleine ve Melody'de 13,7 ve $13,4 \mu \mathrm{g}$ gkt $^{-1}$ olarak belirlenmiştir. Madeleine çeşidinin ortalama sonuçları ise 9,3 (kontrol) ile 17,3 $\mu \mathrm{g} \mathrm{gt}^{-1}$ (AG2) değerleri arasında farklılıklar göstermiştir. Kontrol hariç en düşük ortalama değer $12 \mu \mathrm{g} \mathrm{gkt}^{-1}$ olarak (MG1/2)SG1 varyantlarında belirlenirken en yüksek değerler AG2, MG1 ,AG1ve (MG1/2)AG1 varyantlarında sirasıyla, 17,3, 15,5, 14,4 ve 13,9 olarak belirlenmiştir. Melody çeşidinin ortalama sonuçları ise 11,9 ve $15,8 \mu \mathrm{g} \mathrm{gkt}^{-1}$ değerleri arasında farklılıklar göstermiştir Kontrol hariç en düşük ortalama değerleri AG1SG1 uygulamasında 11,9 (MG1/2)SG1 uygulamasinda 12 ve SG2 uygulamasında $12,4 \mu \mathrm{g} \mathrm{gkt}^{-1}$ olarak belirlenirken en yüksek AG1 uygulamasında 15,8 AG2 uygulamasında 15,3 ve (MG1/2)AG1 uygulamasında $14,5 \mu \mathrm{g} \mathrm{gkt}^{-1}$ olarak belirlenmiştir.

Toprak solunumu değerlerinin uygulamalarla değişimlerine göre bitki çeşit farklılığından kaynaklanan önemli sonuçlar belirlenmemiştir. Bununla beraber gübre uygulamaları $\mathrm{CO}_{2}$ değerlerinde önemli $(p<0,05)$ farklılıklara neden olmuştur. Mineral gübre varyantının birinci dozundan (MG1) daha yüksek $\mathrm{CO}_{2}$ değerleri veren organik uygulamalar sirasıyla, AG1 ve AG2 olarak belirlenirken (MG1/2) AG1 organo-mineral uygulamas1 mineral gübre uygulamalarıyla yakın değerler vermiştir. Araştırma uygulamaları $\mathrm{CO}_{2}$ değerlerinde önemli derecede farklılıklara neden olmuştur. Yapılan benzer bir çalışmada Mandic e-ISSN: 2148-2683 ve ark. (2011), patates bitkisine uygulanan farklı mineral ve organik gübrelemelerin toprak mikrobiyal aktivitelerine etkilerini araştırmışlardır. Araştırma sonucunda çiftlik gübresi uygulamalarının mikroorganizma sayısını arttırdığı belirlenmiştir. Bununla beraber mineral gübre uygulamalarının organizma sayısını azalttığı bildirilmiştir. Aşırı olmayan teşvik seviyesindeki mineral gübre uygulamaları toprak mikrobiyal aktivitesini artırabilir (Fauci and Dick, 1994; Doğan ve ark., 2016). Bununla beraber yüksek dozda ve uzun süreli yapılan özellikle azotlu mineral gübrelemeler toprakların yalnızca mikrobiyal aktivitelerine değil aynı zamanda fiziksel, kimyasal ve biyolojik özelliklerine de zarar verir, toprak kalitesinin düşmesine neden olur (Ayoola and Adeniyan, 2006; Doğan ve ark., 2011). Iovieno ve ark. (2009) tarafından yapılan bir araştırmada, organik ve mineral gübre uygulamalarının $\mathrm{CO}_{2}$ ve enzim aktivitelerine etkileri araştırılmış ve araştırma sonuçlarına göre, organik uygulamaların $\mathrm{CO}_{2}$ değerlerini artırdığı belirlenmiştir. Yapılan benzer birçok araştırma sonuçlarına göre, organik materyal uygulamaları toprak solunumunu ve enzim değerlerini dolayısıyla toprak mikrobiyal aktivitelerini arttırdığı belirlenmiştir (Bastida ve ark., 2008; Iovieno ve ark., 2009; Doğan ve ark., 2016). Yılmaz ve Kurt (2018) tarafindan yapılan bir çalışmada biyokömür ve vermikompost uygulamalarının $\mathrm{CO}_{2}$ üretimini istatistiki olarak etkilemediği belirlenirken, çalışmamızda uygulamaların üretim değerini etkilediği görülmüştür.

\subsection{Dehidrogenaz Enzim Aktivitesi ( $\mu$ g TPF gkt $^{-1}$ )}


Uygulamaların dehidrogenaz enzim aktivitesine (DHA) etkileri Tablo 2'de verilmiştir. Genel ortalama sonuçlarına göre patates çeşitlerinin DHA üzerindeki etkileri benzer çıkmıştır. Tüm uygulamaların DHA değerleri kontrol değerlerinden daha yüksek bulunmuş ve bu artışlar önemli $(p<0,05)$ bulunmuştur. Madeleine çeşidinin ortalama sonuçları ise 152,7 (kontrol) ve 493,5 (AG2) $\mu \mathrm{g}$ TPF $\mathrm{gkt}^{-1}$ değerleri arasında farklılıklar göstermiştir Kontrol haricindeki en düşük DHA değerleri MG2 uygulamasında 163 ve (MG1/2)SG1 uygulamasında 196,1 $\mu \mathrm{g}$ TPF gkt $^{-1}$ olarak belirlenirken en yüksek değerler 493,5 (AG2), 344,2 (AG1) ve 315,6 (AG1SG1) $\mu \mathrm{g}$ TPF $\mathrm{gkt}^{-1}$ olarak belirlenmiştir. Melody çeşidinin ortalama sonuçları ise156 (kontrol) ve 675,2 (AG2) $\mu \mathrm{g}$ TPF gkt $^{-1}$ değerleri arasında farklllıklar göstermiştir. Kontrol haricindeki en düşük DHA değerleri 158,4 ((MG1/2)SG1), 196,8 ((MG1/2)AG1) ve198,7 (SG1) $\mu \mathrm{g}$ TPF gkt $^{-1}$ olarak belirlenirken en yüksek değerler 675,2 (AG2) ve 250,8 (MG1) $\mu \mathrm{g}$ TPF gkt ${ }^{-}$ ${ }^{1}$ olarak tespit edilmiştir.

Melody çeşidinin değerleri Madeleine çeşidine değerlerine göre daha belirsiz ve dalgalı sonuçlar verirken, Madeleine enzim sonuçları daha sabit sonuçlar vermiştir. Toprak mikrobiyal aktivitelerinin önemli bir göstergesi olan DHA, organik materyal uygulamalarından önemli derecede etkilenebilmektedir. Mikroorganizmalar tarafindan salgilanarak, organizmaların organik madde içerisindeki besin ve enerjilere ulaşmasını sağlayan DHA mekanizmasının yoğun olması, ortamdaki organik madde içeriğiyle doğrudan ilişkilidir. Mineral gübreler, organik bağları ve bağ enerjileri olmayan gübreler olduğu için organizma faaliyetlerinden DHA'ya gerek duyulmaz ya da çok az gerek duyulur. $\mathrm{Bu}$ nedenle Mineral gübre uygulamaları DHA değerlerinin düşmesine neden olmuştur. Çiftlik gübresinde, solucan gübresi uygulamalarından daha fazla DHA değerlerinin oluşmasının en önemli olası nedeni ise solucan gübresinin çiftlik gübresinden daha ileri düzeyde ayrışmış olması ve/veya içerdiği bazı antibiyotik ve sindirim enzimleridir (Sparling, 1997; Iovieno ve ark., 2009; Doğan ve ark., 2018; Doğan ve ark., 2020).

\subsection{Mikrobiyal Biyomas Karbon ( $\left.\mu \mathrm{g} \mathrm{gkt}^{-1}\right)$}

Organik ve mineral gübre uygulamalarının patateste kök bölgesi topraklarının MBC'ye etkileri Tablo 2'e verilmiştir. Genel ortalama sonuçlarına göre Madeleine çeşidinde MBC değeri $145,3 \mu \mathrm{g} \mathrm{gkt}^{-1}$ iken Melody çeşidinde ise 130,3 $\mathrm{gg} \mathrm{gkt}^{-1}$ olarak tespit edilmiştir. Mikrobiyal biyomas karbon değerinin çeşitlere göre farklılık gösterdiği tespit edilmiştir. Madeleine çeşidinin mikrobiyal biyomas karbon içeriği ortalama sonuçları 84,6 (SG1) ve 231,9 (AG1SG1) $\mu \mathrm{g} \mathrm{gkt}^{-1}$ değerleri arasında farkl111klar göstermiştir. Melody çeşidinde mikrobiyal biyomas karbon içeriği 64,2 (AG1SG1) ile 222,6 (AG2) aralığında değişim göstermiştir. Her iki çeşit de $\mathrm{MBC}$ değerinin genelde ahır gübresi uygulamasıyla arttığı görülmüştür.

Toprağa uygulanan organik gübrelemenin değerlendirilebilir C (Karbon) kaynağı olmasından dolayı toprakta mikrobiyal biyomas karbon değerini arttırdığı yapılan çalışmalarla bilinmektedir (Yılmaz ve Kurt, 2018). Biyokömür ve vermikompost uygulamalarının da çalışmamıza benzer bir şekilde biyomas karbon değerini arttırdığı belirlenmiştir (Yılmaz ve Kurt, 2018). Kontrol topraklarının sonuçlarına göre herhangi bir uygulama olmaksızın Melody çeşidinin rizosfer aktivitesinin MBC için daha uygun olduğu belirlenmiştir. Solucan gübresi uygulamaları (SG1; SG2) MBC değerlerini düşürmüş olup diğer uygulamaların $\mathrm{MBC}$ değerlerini genel olarak arttırdı̆̆ söylenebilir. Madeleine çeşidi Melody çeşidine göre daha stabil sonuçlar vermiştir. Yapılan benzer bir çalışmada Nakhro ve ark. (2010) organik ve mineral gübre uygulamalarının mikrobiyal popülasyon ve biyomas karbon içeriklerine etkilerini araştırmıştır. Çalışmamızdan farklı olarak bu araştırma sonuçlarına göre organik uygulamaların toprakta $\mathrm{MBC}$ içeriklerini arttırdı ğı bununla beraber inorganik gübre uygulamalarının ise MBC içeriklerini düşürdüğü belirlenmiştir.

\section{Sonuç}

Çiftlik ve solucan gübreleri ile mineral ve kompoze organomineral gübre uygulamalarının patates bitkisinde verim ve kök bölgesi topraklarda $\mathrm{CO}_{2}$, DHA, MBC gibi mikrobiyal aktivitelere etkilerini belirlemek için yapılan bu araştırmanın genel amacı mineral gübre kullanımını azaltarak ekonomik ve ekolojik kazançlar sağlamaktır.

Araştırma sonuçlarına göre mineral gübre uygulamalarına alternatif olarak organik ve organo-mineral gübrelemeler tespit edilmiştir. Mineral gübre dozunun arttırılması toprak kalite unsurlarından mikrobiyal aktivitelere zarar verdiği için mineral gübrenin bu zararları organik gübre karışımlarıyla azaltılabileceği tespit edilmiştir. Çiftlik gübresi uygulaması ile solucan gübresi uygulamaları benzer olumlu sonuçlara neden olurken çiftlik gübresinin solucan gübresinden daha uygun ve ekonomik olduğu sonucuna varılmıştır.

\section{Teșekkür}

Bu çalışma, Hatay Mustafa Kemal Üniversitesi Bilimsel Araştırma Projeleri Koordinasyon Birimi tarafından "19.D.005" kodlu proje ile desteklenmiştir.

\section{Kaynakça}

Akal, M. (2016). Organik ve inorganik gübrelemenin Gümüşhane-Şiran şartlarında patatesin (Solanum tuberosum L.) verim ve verimle ilgili özelliklerine etkileri. Yüksek Lisans Tezi Gaziosmanpaşa Üniversitesi Fen Bilimleri Enstitüsü, Tokat.

Akpınar, M., Şahin, C. B., İşler, N. (2019). The effects of different nitrogen doses on yield and agricultural properties in early potato farming under the Çukurova conditions. Mustafa Kemal Üniversitesi Tarım Bilimleri Dergisi, 24(1), 37-42.

Ayoola, O. T., Adeniyan, O. N., (2006). Influence of poultry manure and NPK fertilizer on yield and yield components of crops under different cropping systems in south west nigeria. Afr. J. Biotechnol., 5(15), 1386-1392.

Bastida, F., Kandeler, E., Moreno, J. L., Ros, M,. García, C, Hernández, T. (2008). Application of fresh and composted organic wastes modifies structure, size and activity of soil microbial community under semiarid climate. Appl Soil Ecol, 40, 318-329. doi:10.1016/ j.apsoil. 2008.05.007.

Boke, S. (2014), Effect of organic and inorganic fertilizer application and seedbed preparation on potato yield and soil properties on alisols of chencha. International Journal of Natural Sciences Research, 2(8), 123-132.

Cerny, J., Balik, J., Kulhanek, K., Casova, K., Nedved, V. (2010). Mineral and organic fertilization efficiency in long-term stationary experiments. Plant Soil Environ, 56(1), 28-26.

Doğan, K., Ağca, N., Karanlik., S. (2020). Effect of earthworm (Annelida Lumbricidae) and organic adding on soil microbial activities in presence of olive mill wastewater. Fresenius Environmental Bulletin, 29(07), 4930-4938. 
Doğan, K., Çelik, İ., Gök, M., Coşkan, A. (2011). Effect of different soil tillage methods on rhizobial nodulation. biyomas and nitrogen content of second crop soybean. African Journal of Microbiology Research, 5(20), 3186-3194.

Doğan, K. Sarioğlu, A. Coskan, A. (2016). Contribution of green manure. rhizobium and humic +fulvic acid on recovering soil biologic activity of olive mill wastewater contaminated soil. Scientific Papers Series A. Agronomy, 59, 63-68.

Doğan, K., Sarığlu, A., Şakar, E., Karanlık, S. (2018). Zeytin karasuyu. 1sıl işlem görmüş solucan gübresi ve çiftlik gübresi uygulamalarının toprak mikrobiyal aktivite değişimlerine etkisi. Süleyman Demirel Üniversitesi Ziraat Fakültesi Dergisi: 1. Uluslararası Tarımsal Yapllar ve Sulama Kongresi Özel Sayısl, 151-159.

Eleroglu, H., Korkmaz, K., (2016). Effects of different organic fertilizers on the yield and quality traits of seed potato cultivars (Solanum Tuberosum L.), Turkish Journal of Agriculture-Food Science and Technology, 4(7), 566-578.

Eyüpoğlu, F. (2002). Türkiye Gübre Gereksinimi Tüketimi ve Geleceği. T.C. Tarım ve Köyişleri Bakanlı̆̆g. Köy Hizmetleri Genel Müdürlügü. Toprak ve Gübre Araştırma Enstitüsü Işletme Müdürlüğü Yayınlarl Teknik Yayın No: T-2, Ankara.

FAO (2018). FAO Production Statistics, http://www.fao.org/faostat/en/\#data/QC, [Date of Access: 09.12.2020].

Fauci, M. F., Dick, R. P., (1994). Soil microbial dynamics: short and long term effect of inorganic and organic nitrogen. Soil Sci. Soc. Am. J, 58(3), 801-806.

Iovieno, P., Morra, L., Leone, A., Pagano, L., Alfani, A., (2009). Effect of organic and mineral fertilizers on soil respiration and enzyme activities of two mediterranean horticultural soils. Biol Fertil Soils, 45, 555-561.

Isermeyer, H. (1952). Eine einfache Methode zur Bestimmung der Bodenatmung und der Karbonate im Böden, Z. Pflanzenaehr. Bodenkd, 5, 56-60.

Kandil, A. A., Attia, A. N., Badawi, M. A,. Sharief, A. E., Abido, W. A. H. (2011). Effect of water stress and fertilization with inorganic nitrogen and organic chicken manure on yield and yield components of potato. Australian Journal of Basic and Applied Sciences, 5(9), 997-1005.

Kannaiyan, S. (2002). Biofertilizers for sustainable crop production. Biotechnology of Biofertilizers, (s. 9-49), Narosa Publishing House, New Delhi.

Karam, F., Rouphac, Y., Lahoud, R., Breidi. J., Coll, G. (2009). Influence of genotypes and potassium application rates on yield and potassium use efficiency of potato. J. Agro, 8(1), 27- 32.

Kılıç, Ş., Ağca, N., Karanlık, S., Şenol, S., Aydın, M., Yalçın, M., Çelik, İ., Evrendilek, F., Uygur, V., Doğan, K., Aslan, S., Çullu, M. A. (2008). Amik ovasının detaylı toprak etütleri, verimlilik çalışması ve arazi kullanım planlaması. Devlet Planlama Teşkilatı (DPT) Projesi, Proje no: DPT2002K120480, Hatay.

Kurt, G. (2019) İnorganik gübreler ile solucan humusu ve leonarditin patates (Solanum tuberosum L.) bitkisinin verim, verim unsurları ve kalite üzerine etkisi. Yüksek Lisans Tezi Atatürk Üniversitesi Fen Bilimleri Enstitüsü, Erzurum.

Mandic, L., Djukić, D., Beatovic, I., Jovovic, Z., Pesakovic, M., Stevovic, V. (2011). Effect of different fertilizers on the microbial activity and productivity of soil under potato cultivation. African Journal of Biotechnology, 10(36), 69546960.

Nakhro, N., Dkhar, MS. (2010). Impact of organic and inorganic fertilizers on microbial populations and biomass carbon in paddy field soil. Journal of Agronomy, 9(3), 102-110.

Öhlinger R, (1993), Bestimmung des Biomasse-Kohlenstoffs mittels Fumigation-Extraktion. In: Schinner. F.. Öhlinger. R.. Kandeler. E.. Margesin. R. (eds) Bodenbiologische Arbeitsmethoden, 2 Auflage, Springer Verlag, Berlin Heidelberg.

Perez, D. V., Alcantara, S., Ribeiro, C. C., Pereira, R.E., Fontes, G. C,. Wasserman, M. A., Venezuela, T. C., Meneguelli, N. A,. De Macedo, J. R. C., Barradas, A. A. (2007). Composted municipal waste effects on chemical properties of a Brazilian soil. Bioresour. Technol, 98, 525-533.

Polat, H. (2020). Türkiye'de kimyasal azotlu gübre tüketim durumunun ve toprak analizi zorunluluğunun azotlu gübre kullanımına etkilerinin değerlendirilmesi, Toprak Su Dergisi, $9(2), 60-71$.

Sarioglu, A,. Dogan, K., Kiziltug, T., Coskan, A., (2017). Organomineral fertilizer applications for sustainable agriculture. Scientific Papers Series A. Agronomy, 60, 161-166.

Sparling, G. P. (1997). Soil microbial biomass. activity and nutrient cycling as indicators of soil health. In: Pankhurst C, Doube BM, Gupta VVSR (eds) Biological Indicators Of Soil Health, Cabinternational, pp 97-119.

Stark, C. Condron, L. M., Stewart, A. D., Di, H. J.. O'callaghan, M. (2007). Influence of organic and mineral amendments on microbial soil properties and processes, Appl. Soil Ecol, 35, 73-93.

Suh, C., Meka, S. S., Ngom, A. F., Neba, D. A., Kemngwa, I. T., Sonkouat, A. D., Njualem, D. (2015). Effects of organic and inorganic fertilizers on growth and yield of potato (Solanum tuberosum L.) in the western highlands of cameroon, International Journal of Development Research, 5(02).

Taheri, N., Sharif-Abad, H. H., Yousefi, K., Roholla-Mousavi, S. (2012). Effect of compost and animal manure with phosphorus and zinc fertilizer on yield of seed potatoes. Journal of Soil Science and Plant Nutrition, 12(4), 705-714.

Tejada, M., Gonzalez, J. (2003). Effects of the application of a compost originating from crushed cotton gin residues on wheat yield under dryland conditions, Eur. Agron, J, 19, $357-$ 368.

Thalman, A. (1967), Über die mikrobielle Aktivitaet und ihre Beziehungen zur Fruchtbarkeitsmerkmalen einiger Ackerböden unter besonderer Berücksichtigung der Dehydrogenase aktivitaet (TTC-Reduktion). Diss. Giessen (FRG).

TÜIK (2019). Bitkisel Üretim İstatistikleri, https://tuikweb.tuik.gov.tr/VeriBilgi.do?alt id=1001, [Erişim tarihi: 09.12.2020].

Yılmaz, F. I., Kurt, S. (2018). Biyokömür ve vermikompost uygulamalarının toprağın bazı biyolojik özellikleri üzerine etkisi. Toprak Bilimi ve Bitki Besleme Dergisi, 6(2), 143-150.

Yourtchi, M. S., Hadi, M. H. S., Darzi, M. T. (2013). Effect of nitrogen fertilizer and vermicompost on vegetative growth, yield and NPK uptake by tuber of potato (Agriacv.). Int. J. Agric. CropSci, 5(18), 2033-2040. 